\title{
Cone Beam Computed Tomography: Adding the Third Dimension
}

\author{
Neha Anil Patil, Rohit Gadda, Rohini Salvi
}

\begin{abstract}
Cone beam computed tomography is a comparatively new threedimensional imaging technology, which has been specially developed for imaging of the maxillofacial complex. The aim of this paper is to accustom the dental fraternity with the wide and potential applications of cone beam computed tomography in dentistry.
\end{abstract}

Keywords: Cone beam computed tomography, Impacted teeth, Dental implants, Endodontics.

How to cite this article: Patil NA, Gadda R, Salvi R. Cone Beam Computed Tomography: Adding the Third Dimension. J Contemp Dent 2012;2(3):84-88.

Source of support: Nil

Conflict of interest: None declared

\section{INTRODUCTION}

Radiology is an important diagnostic tool and selection and application of an appropriate technique helps the dental practitioner arrive at a correct diagnosis. The conventional two-dimensional (2D) intraoral and extraoral radiographic procedures, though very routinely used for evaluation of dental or maxillofacial complex, suffer from several limitations. These limitations are magnification, distortion, superimposition and misrepresentation of structures. ${ }^{1-3}$ With the introduction of cone beam computed tomography (CBCT) in $1997^{4,5}$ imaging the maxillofacial region has become much more accurate and the diagnosis much more precise.

Most of us are familiar with the thin slices which are produced by a helical fan-beam CT also known as medical computed tomography (MDCT), but CBCT allows the creation in 'real-time' of images not only in the axial plane but also 2D images in the coronal, sagittal and even oblique or curved image planes-a process referred to as multiplanar reformation (MPR). In addition, CBCT data are amenable to reformation in a volume, rather than a slice, providing three-dimensional (3D) information (Table 1). ${ }^{2}$

\section{CBCT TECHNOLOGY}

The capturing of an image in CBCT scanner involves a single $360^{\circ}$ rotation of the $\mathrm{X}$-ray source and a reciprocating area detector in synchronization around the patient's head. At certain degree intervals, single projection images, known as 'basis' images, are captured. These are similar to lateral cephalometric radiographic images, each slightly offset from one another. Software programs which have many refined algorithms use these basis projection images to generate a $3 \mathrm{D}$ volumetric data further from which different images in axial, coronal and sagittal planes can be reconstructed. ${ }^{2}$

\section{APPLICATIONS OF CBCT}

\section{Oral and Maxillofacial Surgery}

1. Impacted teeth: CBCT is of great use in assessing the exact position of an impacted or a supernumerary tooth and its relation to the surrounding vital structures. Most commonly impacted teeth are the mandibular third molars. While planning a disimpaction, knowledge about the relation of the tooth to the inferior alveolar nerve canal is of prime importance to avoid any intraoperative or permanent untoward complication. CBCT enables us to assess the exact relation of the tooth to the canal, giving us information of the location of the canal whether buccal/lingual in relation to the tooth and also the

\begin{tabular}{lll} 
& \multicolumn{2}{c}{ Table 1: Comparison of MDCT with $\mathrm{CBCT}^{3}$} \\
\hline Point of comparison & CBCT & MDCT \\
\hline $\begin{array}{l}\text { Shape of the beam } \\
\text { Cost }\end{array}$ & Cone beam & Fan-shaped beam \\
Size of the equipment & Three to 5 times less than MDCT & Costly \\
$\begin{array}{l}\text { Radiation dose } \\
\text { Resolution }\end{array}$ & Substantially lighter and smaller & Heavier and bigger in size \\
Scan time & Due to smaller pixel size better resolution & High (600 micro Sv) \\
$\begin{array}{l}\text { Patient position } \\
\text { Patient convenience }\end{array}$ & Faster scan & Resolution is less as compared to CBCT \\
& Sitting/standing & Long scan time as compared to CBCT \\
& The open design of the equipment & Lying down \\
& along with short scan times and & Patient can experience claustrophobia due to \\
& upright position enhances the patient & closed design of the gantry \\
& convenience and acceptance & \\
\hline
\end{tabular}


proximity of the canal to it. CBCT examination also helps the dental practitioner know the exact number of roots of the tooth planned for extraction their precise position, presence of any dilacerations and analysis of the extent of the pathology related to them, allowing for a defined treatment plan, which would result in less invasive surgical intervention (Fig. 1). ${ }^{2,4-6}$

2. Trauma cases: Another frequent application of CBCT is in assessing fractures of the maxillofacial complex. The conventional 2D imaging has a number of limitations is assessing the exact location and extent of the fracture line, one of the major being superimpositions of the surrounding structures. Though MDCT gives accurate information but the radiation dose to the patient
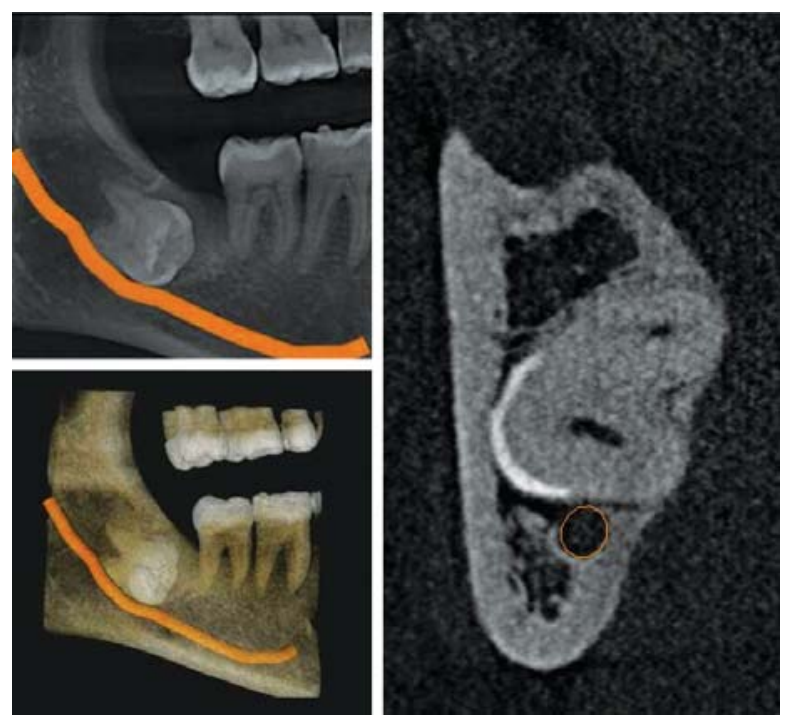

Fig. 1: СBCT images of impacted 48. Reconstructed panoramic image and 3D reconstruction showing horizontally impacted 38 in close approximation to the inferior alveolar nerve canal. Cross section showing the nerve canal is inferior in relation to 38 involved during the scan is reasonably high as is the duration of the scan and the cost. On the contrary, CBCT scanning involves low radiation dose, easy positioning of the patient, short scan time and low cost, thus increasing the patient acceptance. The resolution of the resulting CBCT images is also higher as compared to the MDCT image (Fig. 2).

3. Orthognathic surgery planning: CBCT is also largely used in planning orthognathic surgery which requires detailed visualization of the interocclusal relationship in order to augment the $3 \mathrm{D}$ virtual skull model with a detailed dental surface. ${ }^{7}$

4. Calcified structures in salivary glands: The maximum intensity projection (MIP) images provides valuable information on the distribution and location of soft tissue or vascular calcifications like tonsilloliths, salivary gland stones, calcified lymph nodes and carotid artery calcifications. As the voxel gray scale intensity of these calcified areas is higher than the neighboring voxels, they appear as bright spots on MIP images (Fig. 3).

\section{PERIODONTICS}

CBCT is an accurate tool in assessing the morphologic condition of bone., 8 Many studies have proved that the measurements as performed on the CBCT were at par with the ones done by a periodontal probe. ${ }^{8,10}$ As discussed earlier the superimposition of the surrounding structures as seen on conventional 2D radiographs, hinders the assessment of furcation involvements. On the other hand CBCT specifically helps the periodontist to detect furcation bone loss, buccal lingual defects, fenestrations, dehiscence along with accurate measurement of intra bony defects and evaluate outcome of regenerative periodontal therapy (Fig. 4). 8,10,11
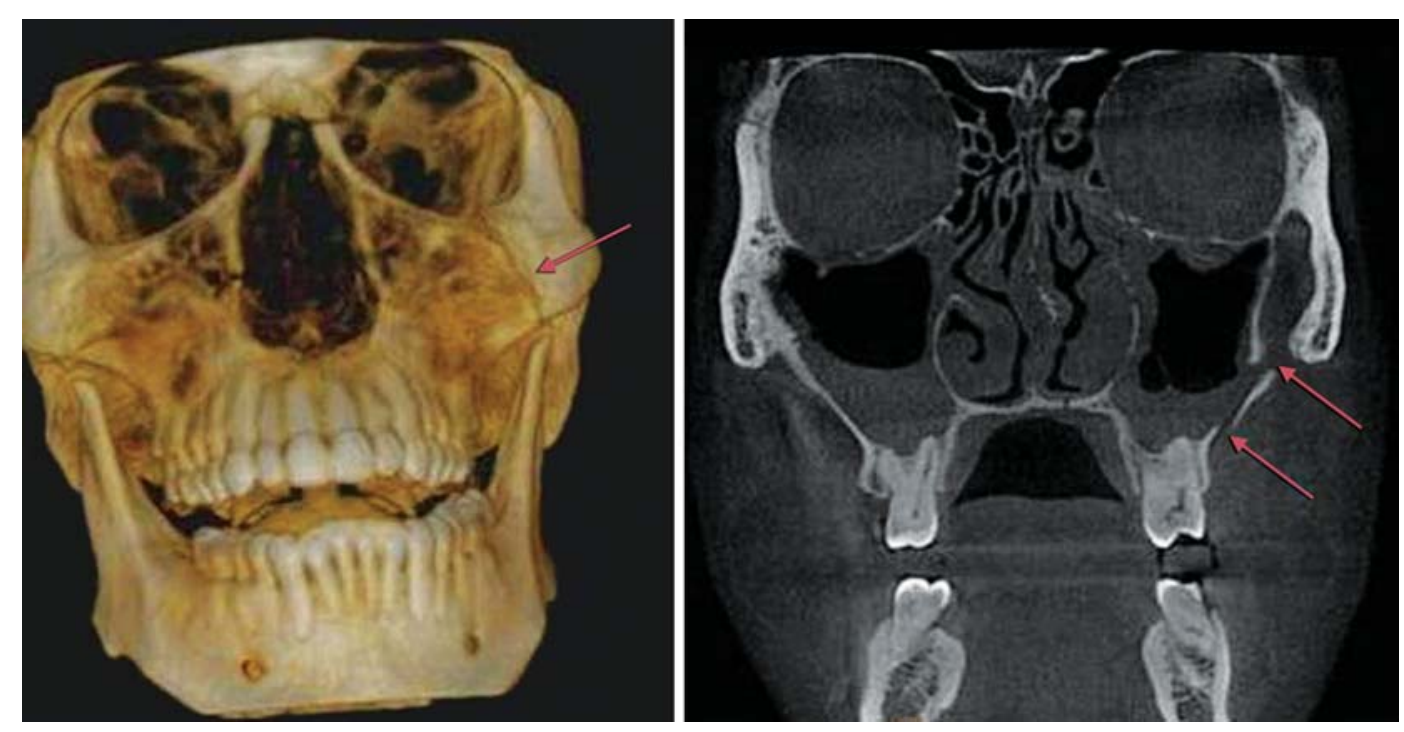

Fig. 2: 3D reconstruction and the coronal section is showing discontinuity suggestive of fracture in relation to the posterolateral wall of the left maxillary sinus 


\section{ENDODONTICS}

An important advantage of CBCT in endodontics is demonstration of anatomic features in 3Ds (axial, coronal, sagittal) which the routine intraoral and panoramic projections cannot. Image enhancement algorithms like zoom magnification, window/level adjustments, and text or arrow annotation can be applied and the cursor-driven measurement algorithms that make possible real-time dimensional assessment which are free from distortion and magnification (Fig. 5). ${ }^{12}$

The applications can be summarized as below: ${ }^{12}$

- Assessing number of root canals and their curvature.

- Diagnosis of dental periapical pathosis.

- Intra- or postoperative assessment of endodontic treatment complications, such as overextended root canal obturation material, separated endodontic instruments, calcified canal identification and localization of perforations.

- Diagnosis and management of dentoalveolar trauma, especially root fractures, luxation and/or displacement of teeth and alveolar fractures.

- Localization and differentiation of external from internal root resorption or invasive cervical resorption from other conditions, and the determination of appropriate treatment and prognosis.
- Presurgical case planning to determine the exact location of root apex/apices and to evaluate the proximity of adjacent anatomical structures.

\section{IMPLANTOLOGY}

MDCT has long been used for measuring the precise height and width of bone for placement of implants. However, the ability of CBCT to provide greater accuracy in measurements at lower radiation doses has made it the preferred option in implant dentistry. ${ }^{13,14}$ The CBCT software does not only allow for measurements of the bone quantity but also helps to measure bone quality ${ }^{15-17}$ along with algorithms with help virtual implant placement. Also there are softwares to construct surgical guides which will further reduce the failure rate. ${ }^{13,18,19} \mathrm{CBCT}$ is also used for bone graft assessment and evaluation of post-treatment cases (Fig. 6). ${ }^{5,20}$

\section{ORTHODONTICS}

CBCT offers a number of advantages for imaging in orthodontics. To list some: ${ }^{21-23}$

- Tooth position and localization

- Measuring bone dimensions for mini-implant placement

- Rapid maxillary expansion
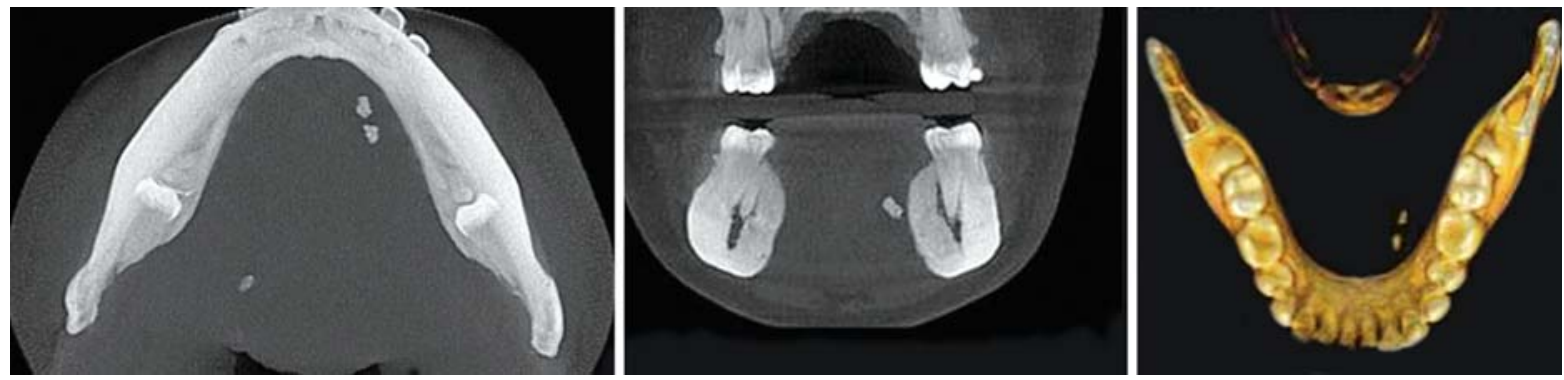

Fig. 3: Axial and coronal sections with 3D reconstructed image show two well-defined structures in the submandibular region suggestive of calcification in the submandibular gland
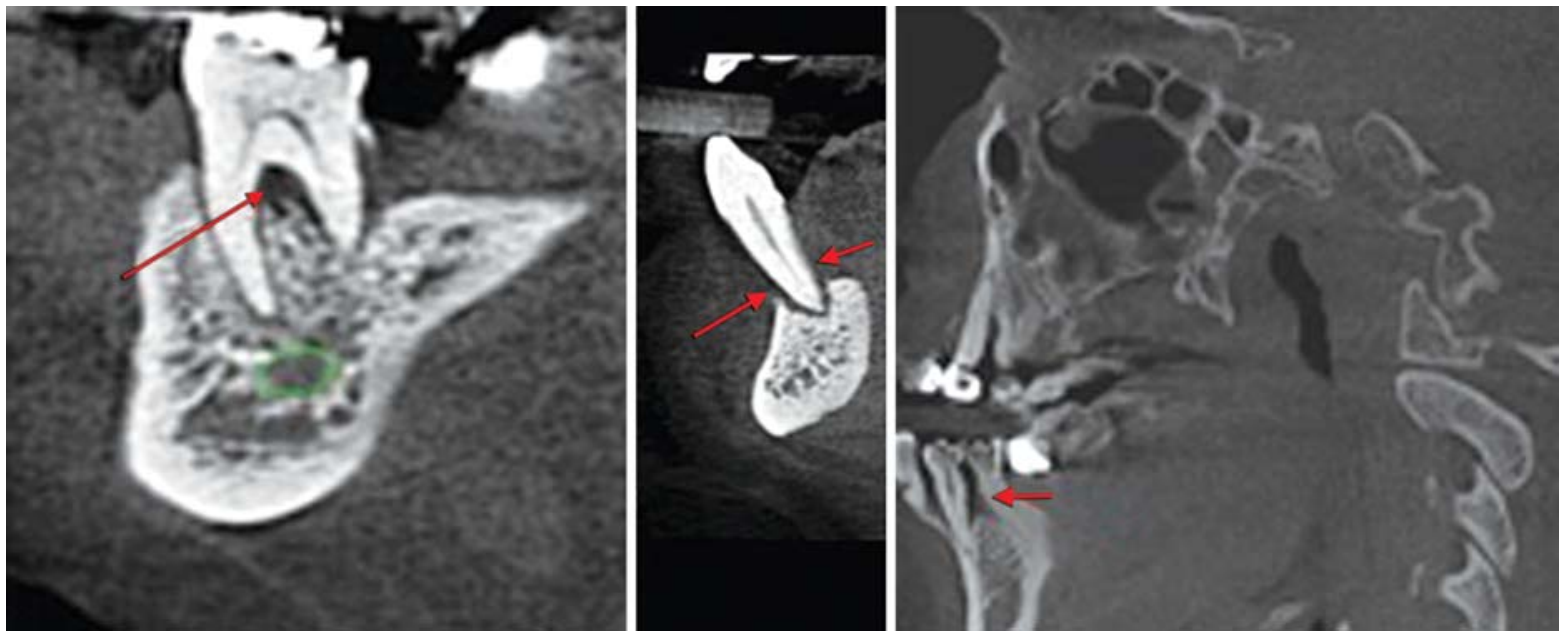

Fig. 4: Clockwise from top: Sagittal section of 38 showing bone loss in the furcation area, cross section of mandibular anterior region showing loss of labial and lingual cortical plates, sagittal section showing interdental bone loss in mandibular premolar area 

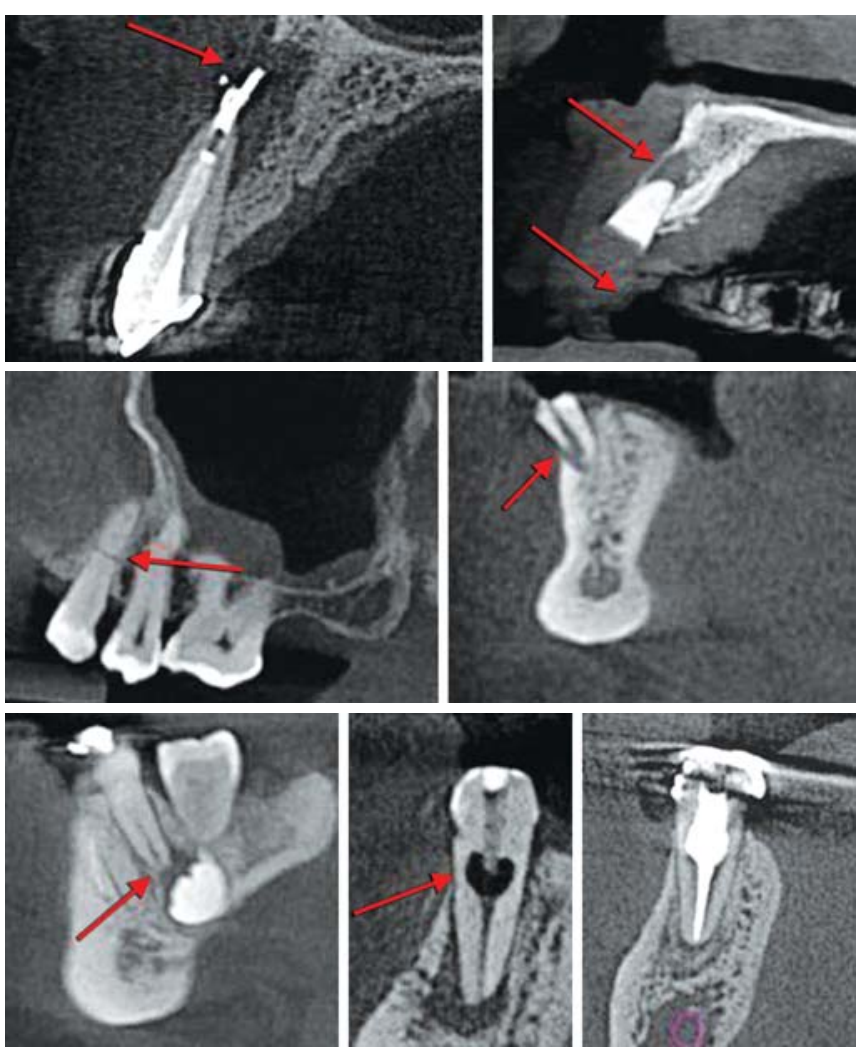

Fig. 5: Clockwise from top: Cross sections showing overextended root canal filling material with a periapical area of very low density suggestive of a periapical pathology, root piece with a periapical pathology, horizontal root fracture of the first premolar, vertical root fracture of canine, external resorption of the distal root of 36 , internal resorption seen in 34,34 postendodontic treatment
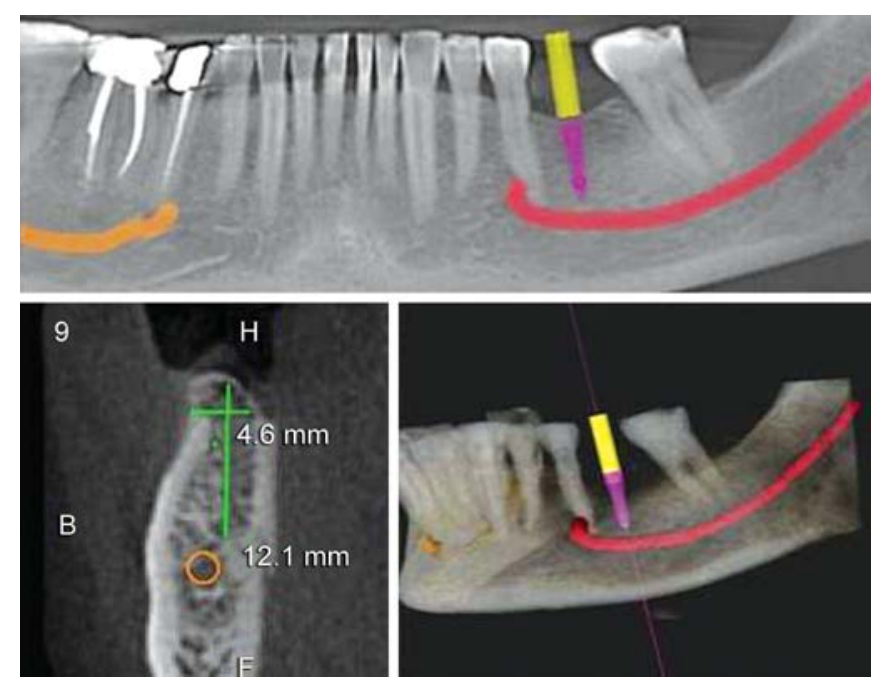

Fig. 6: Reconstructed panoramic and 3D image showing virtual implant placement. Cross section showing height and width of the bone in this region

\section{- 3D cephalometry}

- Airway assessment

- Age assessment

- Orthognathic surgery.

As craniofacial anatomy is precisely described, this meticulous information provided about the anatomical relationships which helps tremendously in better diagnosis, treatment and prognostication. ${ }^{24}$

\section{BONE PATHOLOGIES}

Cysts, tumors and other bony lesions though detected on conventional radiographs, CBCT makes available information pertaining to the actual size of the lesion, its relationship with the surrounding anatomic landmarks and extension of the lesion into paranasal sinuses, orbital cavties, nasopharynx, skull, etc. This added information provided by CBCT images goes ahead in a more accurate diagnosis between inflammatory lesions of the jaws, cysts, odontogenic tumors, nonodontogenic tumors, some other benign conditions like fibrous dysplasia, thalassemia, and even malignant lesions like squamous cell carcinoma, metastatic tumors, osteosarcoma, mucoepidermoid carcinoma, malignant lymphoma, Ewing sarcoma. ${ }^{25,26}$

\section{CONCLUSION}

CBCT provides us with images with have high diagnostic quality with relatively short scanning times (10-70 seconds) and at a low radiation dose, thus finding application in all the dental specialties. To maximize the clinical output further the CBCT data should undergo a thorough clinical evaluation.

\section{ACKNOWLEDGMENT}

The authors gratefully acknowledge ScanDENT Imaging Centre, Matunga, Mumbai, for providing CBCT data for all the figures.

\section{REFERENCES}

1. Calhoun PS, Kuszyk BS, Heath DG, et al. Three-dimensional volume rendering of spiral CT data: Theory and method. Radiographics 1999;19:745-64.

2. Scarfe WC, Farman AG, Sukovic P. Clinical applications of cone-beam computed tomography in dental practice. J Can Dent Assoc 2006;72(1):75-80.

3. Macleod I, Heath N. Cone beam computed tomography (CBCT) in dental practice. Dent Update 2008;35:590-98.

4. Radiation protection: Cone beam CT for dental and maxillofacial radiology. Provisional guidelines 2009 (v1.1 May 2009). A report prepared by the SEDENTEXCT project www.sedentexct.eu. (Retrieved August 2009).

5. Palomo JM, Kan CH, Palomo LB, Hans MG. Three-dimensional cone beam computerized tomography in dentistry. Dent Today 2006;25(11):130-35.

6. Flygare L, Öhman A. Preoperative imaging procedures for lower wisdom teeth removal. Clin Oral Invest 2008;12:291-302.

7. Alamri HM, Sadrameli M, Alshalhood MA, Sadrameli M, Alshehri MA. Applications of CBCT in dental practice: A review of the literature. Gen Dent 2012;60(5):390-400.

8. Tyndall DA, Rathore S. Cone-beam CT diagnostic applications: Caries, periodontal bone assessment, and endodontic applications. Dent Clin North Am 2008 Oct;52(4):825-41. 
9. Vandenberghe B, Jacobs R, Yang J. Diagnostic validity (or acuity) of 2D CCD versus 3D CBCT images for assessing periodontal breakdown. Oral Surg Oral Med Oral Pathol Oral Radiol Endod 2007 Sep;104(3):395-401.

10. Tetradis S, Anstey P, Graff-Radford S. Cone beam computed tomography in the diagnosis of dental disease. J Calif Dent Assoc 2010 Jan;38(1):27-32.

11. Kasaj A, Willershausen B. Digital volume tomography for diagnostics in periodontology. Int J Comput Dent 2007 Apr; 10(2):155-68.

12. Scarfe WC, Levin MD, Gane D, Allan G. Use of cone beam computed tomography in endodontics. Int J Dent 2009;2009: 634567.

13. Dreiseidler T, Mischkowski RA, Neugebauer J, Ritter L, Zöller JE. Comparison of cone beam imaging with orthopantomography and computerized tomography for assessment in presurgical implant dentistry. Int J Oral Maxillofac Implants 2009 Mar-Apr;24(2):216-25.

14. Garg AK. Dental implant imaging: TeraRecon's dental 3D cone beam computed tomography system. Dent Implantol Update 2007 Jun;18(6):41-45.

15. Hatcher DC, Dial C, Mayorga C. Cone beam CT for pre-surgical assessment of implant sites. J Calif Dent Assoc 2003 Nov;31(11): 825-33.

16. Howerton WB Jr, Mora MA. Advancements in digital imaging: What is new and on the horizon? J Am Dent Assoc 2008 Jun;139 Suppl:20S-24S.

17. Hua Y, Nackaerts O, Duyck J, Maes F, Jacobs R. Bone quality assessment based on cone beam computed tomography imaging. Clin Oral Implants Res 2009 Aug;20(8):767-71.

18. Almog DM, LaMar J, LaMar FR, LaMar F. Cone beam computerized tomography based dental imaging for implant planning and surgical guidance, Part 1: Single implant in the mandibular molar region. J Oral Implantol 2006;32(2):77-81.

19. Ganz SD. CT-derived model-based surgery for immediate loading of maxillary anterior implants. Pract Proced Aesthet Dent 2007 Jun;19(5):311-18.
20. Tischler M. In-office cone beam computerized tomography: Technology review and clinical examples. Dent Today 2008 Jun;27(6):102-06.

21. Kumar V, Ludlow JB, Mol A, Cevidanes L. Comparison of conventional and cone beam CT synthesized cephalograms. Dentomaxillofac Radiol 2007;36:263-69.

22. Baumgaertel S, Hans MG. Buccal cortical bone thickness for mini-implant placement Am J Orthod Dentofacial Orthop 2009;136(2):230-35.

23. Harrell WE. 3D Diagnosis and treatment planning in orthodontics. Seminars in Orthodontics 2009;15:35-41.

24. Mah JK, Huang JC, Choo H. Practical applications of conebeam computed tomography in orthodontics. JADA 2010; 141(suppl 3):7S-13S.

25. Boeddinghaus R, Whyte A. Current concepts in maxillofacial imaging. Eur J Radiol 2008;66:396-418.

26. Coti E, Campisi G. Advanced radiographic techniques for the detection of lesions in bone. Endodontic Topics 2004;7:52-72.

\section{ABOUT THE AUTHORS}

\section{Neha Anil Patil}

Senior Lecturer, Department of Oral Medicine and Radiology, MGM Dental College and Hospital, Navi Mumbai, Maharashtra, India

\section{Rohit Gadda (Corresponding Author)}

Senior Lecturer, Department of Oral Medicine and Radiology, MGM Dental College and Hospital, Navi Mumbai, Maharashtra, India e-mail: rohitgadda@gmail.com

\section{Rohini Salvi}

Professor and Head, Department of Oral Medicine and Radiology, MGM Dental College and Hospital, Navi Mumbai Maharashtra, India 